\title{
Melatonin in the Clinical Management of Polycystic Ovarian Syndrome
}

\author{
Kazi Nurul Hasan ${ }^{1}$ and Saumen Kumar Maitra ${ }^{2 *}$ \\ ${ }^{1}$ Department of Zoology, Sidho-Kanho-Birsha University, India \\ ${ }^{2}$ Department of Zoology, Visva-Bharati University, India
}

Submission: October 15, 2018; Published: October 31, 2018

*Corresponding author: Saumen Kumar Maitra, Department of Zoology, Visva-Bharati University, Santiniketan, India

\begin{abstract}
Polycystic ovarian syndrome (PCOS) is one of the most prevalent endocrine disorders affecting women of reproductive age. PCOS is characterized by oligo ovulation and/or anovulation, and excess androgens. Recently, the pineal hormone melatonin earned serious attention for clinical use in the management of PCOS with infertility. Melatonin treatment led to improvement of ovarian functions, oocyte quality, metabolic and hormonal profiles in PCOS. Accumulating studies provide persuasive evidence in favor of the conjecture that melatonin due to its broadspectrum antioxidant property may play a critical role in the care and cure of this syndrome.
\end{abstract}

Keywords: PCOS; Melatonin; Antioxidant; Ovary; Gonadotropins

\section{Introduction}

Polycystic ovarian syndrome (PCOS) is a complexgynecological endocrine disorder that affects many adolescent girls and 6-8\% of women of child-bearing age in epidemic proportions and exhibits a wide spectrum of clinical manifestations [1,2]. This syndrome was first reported in 1935 as a composite clinical disorder for its associations with high androgen levels, hyperinsulinemia and polycystic ovaries [3]. Currently, PCOS is believed to be a heterogeneous disorder resulting from a combined crosstalk among environmental factors and predisposed multifactorial genetic background that leads to the progress of this endocrinopathy [4]. Clinically, PCOS shows various reproductive, metabolic and cardiovascular anomalies, with long-term health concerns during the life span [5]. As a consequence of hormonal imbalance, PCOS leads to the formation of cysts in the ovarian antral follicles beneath the tunica albuginea [6].

In the maturational process of ovum, a large number of ovarian follicles arrest to form small water-filled subcortical cysts, which are characterized as PCOS. In this syndrome, the volume of ovary increases up to $10 \mathrm{~cm} 3$ and more than 12 follicles of less than $10 \mathrm{~mm}$ in diameter in the central dense stroma, and increase in the thickness of follicular sheath and ovarian stroma due to increase in angiogenesis, vasculogenesis, ovarian blood flow and, consequently, reduction or chronic anovulation and infertility [7]. The major clinical hallmarks of this disorder include irregular menstruation, infertility and symptoms associated with an increase in androgens such as hirsutism and acne [8]. Recentyears have witnessed several attempts, especially through management of different hormones, to care and cure of this syndrome, though the outcome of most of the studies is far from being satisfactory.
The purpose of this mini-review is to highlight the findings which project melatonin, a primary hormone of pineal gland, as a potent candidate in the clinical management of polycystic ovarian syndrome with a note on its genesis.

\section{Physiological basis of PCOS}

\section{Hormonal imbalance}

The genesis of PCOS is multi-factorial and largely due to lifestyle errors. The pathophysiology of this syndrome chiefly results from endocrinological deformities, including deregulation of the suprachiasmatic-hypothalamic-pituitary axis or by impairing androgen steroidogenesis [9]. The increased pulsatility of the GnRH neurons triggers increased androgen secretion from the theca cells mediated by persistently high LH/FSH ratio. LH propelled hyperthecosis and increased androgen levels arrests follicular growth and impairs follicular maturation [10]. Apart from this, ovarian steroidogenic enzyme deficiencies such as $3 \beta$-hydroxysteroid dehydrogenase (3 $\beta$-HSD) and aromatase can trigger hyperandrogenemia and hypoestrogenemia resulting of the phenotype of PCOS $[7,11]$. Several hormonal markers like insulin-like growth factor-1 (IGF-1), total/free testosterone, androstenedione, dehydroepiandrosterone (DHEA), 17-hydroxyprogesterone have been identified in the PCOS patients accordingly [4].

\section{Oxidative stress}

Generation of oxidative stress in the ovary may lead to PCOS with several clinical phenotypes like atherosclerotic lesions, insulin resistance, obesity, hyperandrogenemia, and infertility 
[7]. The levels of oxidative stress marker, (e.g., malondialdehyde), and different enzymatic and non-enzymatic antioxidants like superoxide dismutase (SOD), catalase (CAT), reduced glutathione (GSH), glutathione peroxidase (GPx), paroxanase and glutathione S-transferase M3 (GSTM3) are measured to evaluate the levels of oxidative stress in the women with PCOS [12]. Lifestyle adjustments, exercise, optimizing caloric intake and diet loaded with antioxidants favorably modulate the redox imbalance with a resultant decline in oxidative stress induced PCOS.

\section{Treatment of PCOS}

Currently, apart from surgery, the most recognized treatment of PCOS is the use of medicines like, clomiphene citrate, metformin, letrozole and tamoxifen [7]. But they have prolonged side effects. Thus extensive research is carried out to find out alternative medicine for treating PCOS. Nowadays, melatonin (MEL), due to its strong antioxidant property, is in focal attention in the care and cure of PCOS. Though the pineal gland is the primary source of circulating melatonin, the mammalian ovary, as a whole, the granulosa cells, the oocyte, and those making up the cumulus oophorus have been reported to synthesize MEL i.e., endogenous in origin [13]. Higher MEL level in the preovulatory follicles helps to protect the granulosa cells from free radical damage and ultimately hinders the development of PCOS by improving the oocyte quality [1].

\section{Action of melatonin on steroidogenesis}

Melatonin is acknowledged for exerting a very relevant role in modulating ovarian functions and oocyte maturation [14]. In the ovary, MEL is known to be associated with progesterone production by the transforming granulosa cells after ovulation by regulating the activities of steroidogenic enzymes or their expression at gene level in theca and granulose cells to decrease the level of androgens. Though the complete story is yet been untold, it is hypothesized that MEL treatment may significantly help to maintain LH/FSH balance as well as the level of gonadal androgens to control the development of PCOS [9] via MT1 and MT2 receptor proteins [15] (Figure 1). MEL is also effective in the regulation of LH receptor gene expression, and gonadotropinreleasing hormone receptor gene expression in human granulosalutein cells via the mitogen-activated protein kinase (MAPK) pathway [16].

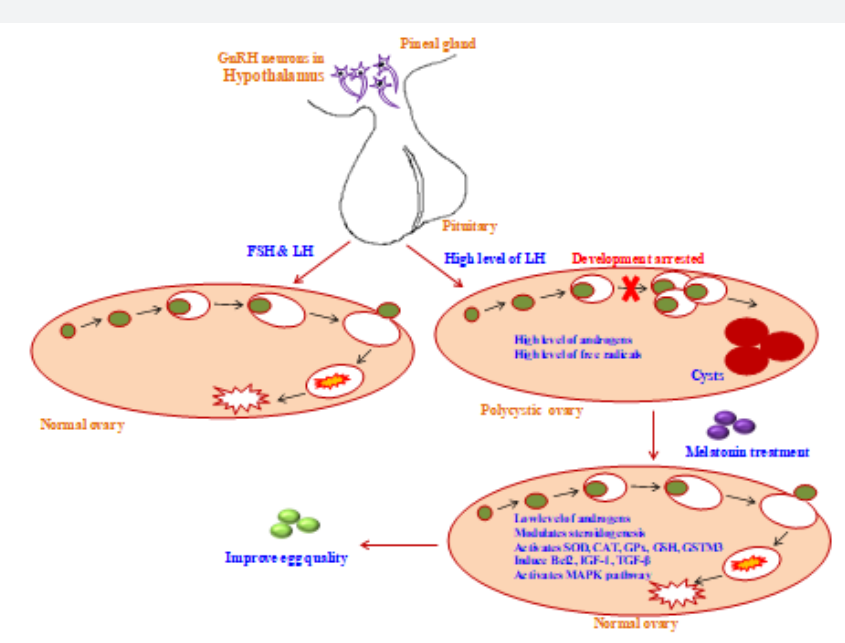

Figure 1: Diagrammatically presented summary of existing information explains possible role of melatonin in the care and cure of PCOS See text for abbreviations.

\section{Action of melatonin on oxidative stress}

In PCOS, generation of ROS from mononuclear cells and lipid peroxidation products in serum are significantly elevated, and activities of antioxidative enzymes (SOD, CAT, GPx) become reduced, that ultimately may contribute to oxidative stress mediated apoptosis in atretic follicles. MEL prevents apoptosis by inducing Bcl2 expression and reducing Casp3 activity. MEL may increase IGF-1 and transform growth factor-beta (TGF- $\beta$ ) production, which are anti-apoptotic [17]. Thus, normally the increase in follicular MEL concentrations in the growing follicles could be an important factor in avoiding atresia. A very recent study suggested that MEL $(10 \mathrm{mg} / \mathrm{kg})$ significantly decreases the PCOS phenotypes in mice due to its antioxidant properties [7]. In women, chronic administration of melatonin with PCOS $(2 \mathrm{mg} /$ day for six months) significantly decreased testosterone levels and reduced menstrual irregularities [18]. Sleep disturbances in women with PCOS is frequently-reported. As melatonin assists in sleep, its beneficial effect in PCOS is understandable [8]. Ovarian follicles may be rescued from PCOS by MEL and thus allow a preovulatory follicle to fully develop and provide a healthy oocyte for fertilization.

\section{Conclusion}

The pineal hormone melatonin is known to regulate a variety of central and peripheral actions related to circadian rhythms. It is a pleiotropic molecule, which plays a vital role in female reproduction as a powerful free radical scavenger and involves in many gynecological and obstetrical pathology. Though the studies 
advocating potential role of melatonin as a new therapeutic agent for PCOS diagnosed women, more multi-dimensional studies are warranted to validate the preliminary results and eventually aim at reducing as the treatment goal of PCOS.

\section{References}

1. Yang HL, Zhou WJ, Gu CJ, Meng YH, Shao J et.al, (2018) Pleiotropic roles of melatonin in endometriosis, recurrent spontaneous abortion, and polycystic ovary syndrome. Am J Reprod Immunol 80(1): e12839.

2. Khan KA, Stas S, Kurukulasuriya LR (2006) Polycystic ovarian syndrome. J Cardiometab Syndr 1(2): 125-30.

3. Burghen GA, Givens JR, Kitabchi AE (1980) Correlation of hyperandrogenism with hyperinsulinism in polycystic ovarian disease. J Clin Endocrinol Metab 50(1): 113-6.

4. Azziz R, Carmina E, Dewailly D, Diamanti-Kandarakis E, EscobarMorreale HF, et al. (2009) The androgen excess and PCOS society criteria for the polycystic ovary syndrome: the complete task force report. Fertil Steril 91(2): 456-88.

5. Orio F, Palomba S (2014) Reproductive endocrinology: new guidelines for the diagnosis and treatment of PCOS. Nat Rev Endocrinol 10(3): $130-2$.

6. Azziz R, Sanchez LA, Knochenhauer ES, Moran C, Lazenby J, et al. (2004) Androgen excess in women: experience with over 1000 consecutive patients. J Clin Endocrinol Metab. 89(2): 453-62.

7. Ahmadi M, Rostamzadeh A, Fathi F, Mohammadi M, Rezaie MJ, et al. (2017) The effect of melatonin on histological changes of ovary in induced polycystic ovary syndrome model in mice. Middle East Fertil Soc J 22(4): 255-9.

8. Patel S (2018) Polycystic ovary syndrome (PCOS), an inflammatory, systemic, lifestyle endocrinopathy. J Steroid Biochem Mol Biol 182: 2736.

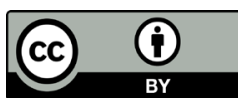

This work is licensed under Creative

Commons Attribution 4.0 License

DOI: 10.19080/JOJNHC.2018.09.555770
9. Monastra G, Unfer V, Harrath AH, Bizzarri M (2017) Combining treatment with myo-inositol and D-chiro-inositol (40:1) is effective in restoring ovary function and metabolic balance in PCOS patients. Gynecol Endocrinol 33(1): 1-9.

10. Bruni V, Dei M, Nannini S, Balzi D, Nuvolone D, et al. (2010) Polycystic ovary syndrome in adolescence. Ann NY Acad Sci 1205: 175-84.

11. Belgorosky A, Pepe C, Marino R, Guercio G, Saraco N, et al. (2003) Hypothalamic-pituitary-ovarian axis during infancy, early and late prepuberty in an aromatase-deficient girl who is a compound heterocygote for two new point mutations of the CYP19 gene. J Clin Endocrinol Metab 88(11): 5127-2131.

12. Younis A, Hawkins K, Mahini H, Butler W, Garelnabi M, et al. (2014) Serum tumor necrosis factor- $\alpha$, interleukin- 6 , monocyte chemotactic protein-1 and paraoxonase- 1 profiles in women with endometriosis, PCOS, or unexplained infertility. J Assist Reprod Genet 31(11): 14451451.

13. Sakaguchi K, Itoh MT, Takahashi N, Tarumi W, Ishizuka B, et al. (2013) The rat oocyte synthesises melatonin. Reprod Fertil Dev 25(4): 674-682.

14. Tamura H, Nakamura Y, Korkmaz A, Manchester LC, Tan D-X, et al (2009) Melatonin and the ovary: physiological and pathophysiological implications. Fertil Steril 92(1): 328-343.

15. Jain P, Jain M, Haldar C, Singh TB, Jain S, et al. (2013) Melatonin and its correlation with testosterone in polycystic ovarian syndrome. J Hum Reprod Sci 6(4): 253-258.

16. Woo MMM, Tai CJ, Kang SK (2001) Direct action of melatonin in human granulosa-luteal cells. J Clin Endocrinol Metab 86(10): 4789-4797.

17. Maitra SK, Hasan KN (2017) Melatonin in the care and control of human health. JOJ Nurse Health Care 4(3): 555640.

18. Tagliaferri V, Romualdi D, Scarinci E, Cicco S, Florio CD, et al. (2018) Melatonin treatment may be able to restore menstrual cyclicity in women with PCOS: A pilot study. Reprod Sci 25(2): 269-275.

\section{Your next submission with Juniper Publishers will reach you the below assets}

- Quality Editorial service

- Swift Peer Review

- Reprints availability

- E-prints Service

- Manuscript Podcast for convenient understanding

- Global attainment for your research

- Manuscript accessibility in different formats

(Pdf, E-pub, Full Text, Audio)

- Unceasing customer service

Track the below URL for one-step submission https://juniperpublishers.com/online-submission.php 